\title{
Uncertainties in future climate predictions due to convection parameterisations
}

\author{
H. Rybka and H. Tost \\ Institute for Atmospheric Physics, University of Mainz, Mainz, Germany \\ Correspondence to: H. Rybka (rybkah@uni-mainz.de)
}

Received: 1 August 2013 - Published in Atmos. Chem. Phys. Discuss.: 16 October 2013

Revised: 31 March 2014 - Accepted: 7 April 2014 - Published: 5 June 2014

\begin{abstract}
In the last decades several convection parameterisations have been developed to consider the impact of small-scale unresolved processes in Earth System Models associated with convective clouds. Global model simulations, which have been performed under current climate conditions with different convection schemes, significantly differ among each other in the simulated transport of trace gases and precipitation patterns due to the parameterisation assumptions and formulations, e.g. the computation of convective rainfall rates, calculation of entrainment and detrainment rates etc. Here we address sensitivity studies comparing four different convection schemes under alternative climate conditions (with doubling of the $\mathrm{CO}_{2}$ concentrations) to identify uncertainties related to convective processes. The increase in surface temperature reveals regional differences up to $4 \mathrm{~K}$ dependent on the chosen convection parameterisation. These differences are statistically significant almost everywhere in the troposphere of the intertropical convergence zone. The increase in upper tropospheric temperature affects the amount of water vapour transported to the lower stratosphere, leading to enhanced water vapour contents between $40 \%$ and $60 \%$ at the cold point temperature in the Tropics. Furthermore, the change in transporting short-lived pollutants within the atmosphere is highly ambiguous for the lower and upper troposphere. These results reflect that different approaches to compute mass fluxes, detrainment levels or trigger functions determine the transport of short-lived trace gases from the planetary boundary layer to lower, middle or upper tropospheric levels. Finally, cloud radiative effects have been analysed, uncovering a shift in different cloud types in the Tropics, especially for cirrus and deep convective clouds. These cloud types induce a change in net cloud radiative forcing varying from $0.5 \mathrm{~W} \mathrm{~m}^{-2}$ to $2.0 \mathrm{~W} \mathrm{~m}^{-2}$.
\end{abstract}

\section{Introduction}

Climate change due to increasing anthropogenic emissions is usually predicted with the help of Earth system models (ESMs). A typical measure associated with future climate predictions is the equilibrium climate sensitivity, defined as the change in global mean temperature at the surface caused by a doubling of the carbon dioxide concentration (Cess et al., 1990). The increase in greenhouse gases influences the incoming and outgoing radiation, consequently modifying the energy and heat budget of the atmosphere and the ocean accompanied by a redistribution of water vapour. Both heat and water vapour budgets are strongly coupled with atmospheric moist convection, which generally cannot be resolved directly in global atmospheric models. The parameterisation of convection, which represents small-scale cloud processes, induces much of the uncertainty concerning predictions of climate variability (Randall et al., 2003; Arakawa, 2004). In the last decades a variety of convection schemes have been developed (i.e. Arakawa and Schubert, 1974; Tiedtke, 1989; Hack, 1994; Zhang and McFarlane, 1995; Emanuel and Zivkovic-Rothman, 1999; Grabowski and Smolarkiewicz, 1999; Donner et al., 2001; Bechtold et al., 2001; Lin and Neelin, 2003; Nober and Graf, 2005; Khairoutdinov et al., 2005; Plant and Craig, 2008). Some of them are slightly different, whereas most of them vary significantly in the description of convective processes. In principle, every scheme attempts to describe the statistical effect of moist convection to adjust the energy and water budget of the atmosphere into a more stable state.

Previous studies have compared different convection parameterisations in an ESM applying current climate conditions. The results indicate large differences in the simulated water vapour distribution and in the transport of short-lived 
Table 1. Convection parameterisations applied in the individual simulations; to differentiate between the reference simulation, $2 \times \mathrm{CO}_{2}$ simulation and the two resolutions the following abbreviations are added to the simulation name: REF or $2 \times \mathrm{CO} 2$ and $\mathrm{T} 42$ or T63.

\begin{tabular}{cl}
\hline Simulation name & Description \\
\hline T1 & $\begin{array}{l}\text { Tiedtke scheme with modifications of } \\
\text { Nordeng (Tiedtke, 1989; Nordeng, 1994) }\end{array}$ \\
EC & $\begin{array}{l}\text { IFS cycle 29r1b from ECMWF (Bechtold } \\
\text { et al., 2004) }\end{array}$ \\
EM & $\begin{array}{l}\text { Emanuel and Zivkovic-Rothman (1999) } \\
\text { Combined scheme of Zhang and McFar- } \\
\text { ZM }\end{array}$ \\
& $\begin{array}{l}\text { lane (1995) and Hack (1994) with a mod- } \\
\text { ification of Wilcox (2003) }\end{array}$ \\
\hline
\end{tabular}

trace gases due to a change of the convection scheme (Mahowald et al., 1997; Tost et al., 2006, 2010; Zhang et al., 2008). The region with the highest sensitivity is the upper troposphere-lower stratosphere (UTLS) in the intertropical convergence zone (ITCZ), which is dominated by the ascending vertical motion driven by convective cells. Therefore, it is anticipated that these uncertainties will propagate to alternate and future climate predictions.

Another major source of uncertainty regarding model projections of global warming is the effect of clouds on the radiation budget (Stephens, 2005; Solomon et al., 2007). The huge spread of simulated cloud radiative feedbacks, occurring among climate models for more than a decade, has been observed in several studies (Cess et al., 1989; Colman, 2003; Soden and Held, 2006; Bony et al., 2006) and recognised as a key factor of the uncertainty in climate change since the 1970s (i.e. Charney, 1979). The complexity of this problem is attributed to cloud-induced flux changes (so-called cloud radiative forcing, $\mathrm{CRF}$ ) of the net short-wave and long-wave radiation compared to clear-sky conditions. The modification of clouds on the radiative fluxes in the atmosphere is strongly dependent on the specific cloud type and can substantially vary in magnitude and sign (Chen et al., 2000; Hartmann et al., 1992, 2001). Areas which contribute the most to intermodel differences of simulated CRFs are regimes of moderate subsidence in tropical regions reflecting low-level clouds in trade wind regions (Bony et al., 2004). These regimes are often closely related to deep convective cells, which influence regions of mean subsidence (Emanuel et al., 1994; Larson et al., 1999). Consequently, convection schemes alter cloud radiative forcing and its feedback.

Since convection schemes interact with large-scale cloud parameterisations, which describe the process of condensation and evaporation on the grid scale, and consequently cloudiness and precipitation, their interdependency (subgridscale $\leftrightarrow$ large-scale processes) influences total precipitation patterns and the amount and type of clouds, thus affecting cloud radiation properties (Hourdin et al., 2006).

Here we present an intercomparison of 16 simulations that differ with respect to the convection parameterisation, climatic distinction and model resolution. The focus is to identify and quantify uncertainties in simulated temperature increase, cloud radiative forcing and transport processes due to changes induced by the usage of different convection parameterisations. In order to avoid ambiguities, the term "sensitivity" is used in the sense of "sensitivity of cloud radiative feedbacks to convection parameterisation". These cloud radiative feedbacks certainly influence the sensitivity of the climate system (Colman, 2003; Ringer et al., 2006; Bony et al., 2006).

This study extends sensitivity studies of convection parameterisations which have been performed under current climate conditions (Tost et al., 2006, 2010). It was shown that an exchange of the convection parameterisation significantly modifies the water vapour and temperature distribution in the UTLS region, especially in low latitudes. Furthermore, discrepancies in precipitation patterns and cloudiness have been found to alter the radiation and energy budget of the atmosphere. This work focuses on the impact of different convection schemes influencing meteorological variables under climate change conditions.

In Sect. 2 an overview of the model and simulation setup is given. Section 3 concerns with mathematical methods, which are used to interpret the results in Sect. 4. The results are divided into several subsections dealing with differences in the temperature distribution, precipitation, transport of shortlived trace gases and the cloud radiative forcing. Our conclusions are given in Sect. 5 .

\section{Model description and simulation setup}

\subsection{Model description}

To analyse the impact of convection parameterisations the ECHAM5/MESSy atmospheric chemistry model (EMAC, Joeckel et al., 2010) is used. It is a combination of the fifth generation of the European Centre Hamburg general circulation model (ECHAM5, Roeckner et al., 2006) and the Modular Earth Submodel System (MESSy, Joeckel et al., 2005). The former calculates the atmospheric flow with the prognostic variables (vorticity, divergence, temperature, total moisture and the logarithm of the surface pressure) and is integrated in the Base Model Layer of MESSy (Joeckel et al., 2005). The interface structure of MESSy allows the use of different submodels linking modules for atmospheric chemistry, transport or diagnostic tools with the meteorology. The modularisation implies an equivalent configuration for every simulation, distinguishing only by the chosen convection parameterisation in the submodel CONVECT and the carbon dioxide concentration of the atmosphere used in the radiation 
calculations (submodel RAD4ALL). The implementation of atmospheric chemistry processes is neglected, as well as the simulation of the ocean circulation. The latter consequently determines the requirement of boundary conditions (e.g. sea surface temperatures and sea ice content) for the simulations.

\subsection{Simulation setup}

For this study two scenarios are calculated with EMAC (Roeckner et al., 2006; Joeckel et al., 2005, 2010), applying for each four different convection schemes (see Table 1). Additional information about the individual convection parameterisations and their implementation are described in Tost et al. (2006) and references therein. Each set of experiments includes a reference simulation (hereafter referred to as REF) with a carbon dioxide concentration of $348 \mathrm{ppm}$ and a double- $\mathrm{CO}_{2}$ simulation (abbr. $2 \times \mathrm{CO} 2$ ) with a $\mathrm{CO}_{2}$ concentration of $696 \mathrm{ppm}$. Oceanic boundary conditions are prescribed with external data. For this purpose, climatological monthly average sea surface temperature (SST) and sea ice content (SIC) from 1987 to 2006 from the AMIP database are used for the reference simulation. Concerning the $2 \times \mathrm{CO} 2$ simulation, data of a coupled atmosphere-ocean general circulation model (increased/decreased SSTs/SICs), which has been run under similar climate conditions $\left(\mathrm{CO}_{2}\right.$ concentration of $696 \mathrm{ppm}$ ), have been used to maintain the radiative equilibrium (Ponater, 2012, personal communication). Two horizontal resolutions (T42 and T63) are applied with 31 vertical hybrid pressure levels up to $10 \mathrm{hPa}$ for each simulation, which results in 16 simulations spanning a space of the chosen convection parameterisation, resolution and climate condition. The time step is 10 minutes for both resolutions.

The simulation period spans 10 years, considering the first year of the simulation as spin-up and therefore discarding it from the analysis in each case. Monthly averaged output data have been used for the analysis. It should be mentioned that because of the coarse vertical resolution for the stratosphere, circulation patterns in these altitudes are insufficiently resolved. Consequently, results for these regions should be treated carefully.

\section{Methods}

The variety of simulations allows many possibilities for comparisons; therefore a consistent notation is required to avoid possible confusion. To compare a variable $x$ of two (or more) simulations the following notation is used.

The symbol $\Delta$ indicates the difference between the $2 \times \mathrm{CO} 2$ and REF simulation considering the same convection scheme $(i=\mathrm{T} 1, \mathrm{EC}, \mathrm{EM}$ or $\mathrm{ZM})$ in both runs, i.e.

$\Delta x_{i}=x_{i, 2 \times \mathrm{CO} 2}-x_{i, \mathrm{REF}}$.

To identify the differences between two individual simulations with the same $\mathrm{CO}_{2}$ concentration the character $\delta$ and
Table 2. Calculated temperature increase $\Delta T$, inter-annual variability $\sigma$ (one standard deviation) and temperature difference $\delta$ for the lowermost model layer (horizontally area weighted) with $\mathrm{T} 1$ as the reference simulation.

\begin{tabular}{cccc|ccc}
\hline & \multicolumn{3}{c|}{$\mathrm{T} 63$} & \multicolumn{3}{c}{$\mathrm{T} 42$} \\
run & $\Delta T$ & $\delta_{\mathrm{T} 1}^{i}(\Delta T)$ & $\sigma(\Delta T)$ & $\Delta T$ & $\delta_{\mathrm{T} 1}^{i}(\Delta T)$ & $\sigma(\Delta T)$ \\
& $(\mathrm{K})$ & $(\mathrm{K})$ & $(\mathrm{K})$ & $(\mathrm{K})$ & $(\mathrm{K})$ & $(\mathrm{K})$ \\
\hline $\mathrm{T} 1$ & 3.4 & - & 0.06 & 3.3 & - & 0.04 \\
$\mathrm{EC}$ & 3.5 & 0.12 & 0.06 & 3.5 & 0.26 & 0.12 \\
$\mathrm{EM}$ & 3.3 & -0.06 & 0.08 & 3.3 & 0.04 & 0.06 \\
$\mathrm{ZM}$ & 3.4 & -0.03 & 0.06 & 3.4 & 0.07 & 0.08 \\
\hline
\end{tabular}

subscripts distinguishing the convection schemes are applied. For example, the difference of a variable $x$ between the REF simulations of EM and $\mathrm{T} 1$ is calculated as follows:

$\delta_{\mathrm{T} 1}^{\mathrm{EM}} x_{\mathrm{REF}}=x_{\mathrm{EM}, \mathrm{REF}}-x_{\mathrm{T} 1, \mathrm{REF}}$.

The combination of Eq. (1) and (2) results in

$$
\begin{aligned}
\delta_{\mathrm{T} 1}^{\mathrm{EM}}(\Delta x) & =\Delta x_{\mathrm{EM}}-\Delta x_{\mathrm{T} 1} \\
& =\left(x_{\mathrm{EM}, 2 \times \mathrm{CO} 2}-x_{\mathrm{EM}, \mathrm{REF}}\right) \\
& -\left(x_{\mathrm{T} 1,2 \times \mathrm{CO} 2}-x_{\mathrm{T} 1, \mathrm{REF}}\right),
\end{aligned}
$$

where $\delta_{j}^{i}(\Delta x)$ represents the uncertainty of a changing quantity $x$ between two convection schemes (whereas $i, j=\mathrm{T} 1$, $\mathrm{EC}, \mathrm{EM}$ or $\mathrm{ZM}$ and $i \neq j$ ). Finally, a measure is needed to compute the maximum error or variability of a variable due to a change of the convection parameterisation for one resolution:

$$
\begin{aligned}
x_{\mathrm{Var}} & =x_{\mathrm{max}}-x_{\min }, \\
\text { where } \quad x_{\max } & =\operatorname{MAX}\left(x_{\mathrm{T} 1}, x_{\mathrm{EC}}, x_{\mathrm{EM}}, x_{\mathrm{ZM}}\right), \\
\text { and } \quad x_{\min } & =\operatorname{MIN}\left(x_{\mathrm{T} 1}, x_{\mathrm{EC}}, x_{\mathrm{EM}}, x_{\mathrm{ZM}}\right) .
\end{aligned}
$$

Equation (4) displays the maximum error by selecting the minimum value $x_{\min }$ of four simulations at a specific grid point (and/or level) and subtracting it from the corresponding maximum value $x_{\max }$ at the same location.

For the following section, one has to keep in mind that the analysed variables are 9-year averaged values of the monthly output data.

\section{Results}

\subsection{Temperature}

As convection influences the atmospheric heat budget and consequently the temperature profile (Yanai et al., 1973; Johnson, 1984), differences in the temperature profiles of the $\mathrm{REF}$ and $2 \times \mathrm{CO} 2$ simulations are analysed.

Figures 1a and c show the simulated global mean temperature increase/decrease $(\Delta T)$ in the troposphere/stratosphere due to a doubling of the carbon dioxide concentration and 
(a) $\mathrm{T} 63$

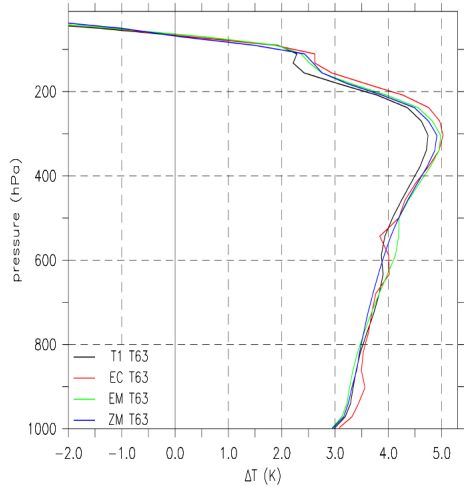

(b) $\mathrm{T} 63$ - $\mathrm{T} 42$

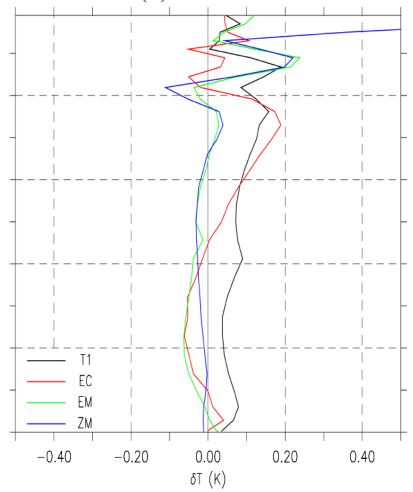

(c) $\mathrm{T} 42$

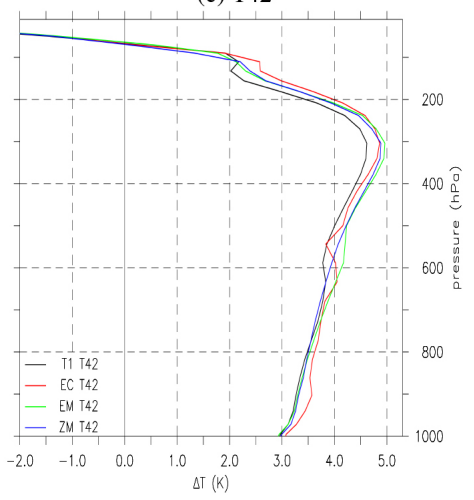

Figure 1. Temperature difference $\Delta T$ of the global mean temperature profiles between the $2 \times \mathrm{CO} 2$ and REF simulations for different convection parameterisations and two resolutions (left panel: T63; right panel: T42). The figure in the middle displays the temperature difference of the two resolutions.

the application of different convection parameterisations and model resolutions. Qualitatively, the general characteristics of the vertical temperature change profile are independent of the selected resolution and convection scheme: a gradual increase from $3 \mathrm{~K}$ to $5 \mathrm{~K}$ up to $300 \mathrm{hPa}$ accompanied by a gain in radiative energy which is not uniformly distributed within the troposphere because of advection and convective mixing. In contrast, the stratospheric temperature decrease is related to enhanced absorption and re-emission of higher $\mathrm{CO}_{2}$ concentrations. The differences between individual simulations are on average below $0.5 \mathrm{~K}$, but show significant variations around $600 \mathrm{hPa}$ and above $400 \mathrm{hPa}$. These two regions of high model-to-model fluctuations are related to two mechanisms associated with different formalisms in the convection schemes.

Firstly, the representation of microphysics strongly influences the formation of precipitation as well as ice and snow formation and is therefore connected to the release and/or need of energy for phase transformations, especially around $600 \mathrm{hPa}$. In addition to this, detrainment rates for midlevel convection, which are enhanced in the EC simulations, influence the occurrence and amount of precipitation (Wang et al., 2007). Secondly, the transport of water vapour by convective updrafts to high altitudes affects the radiation, thereby altering the temperature above $400 \mathrm{hPa}$. These two processes are the major reasons for the variability in the temperature change between the individual simulations. The comparison of Fig. 1a, $\mathrm{c}$ is shown by a difference diagram in Fig. 1b. The $\mathrm{T} 1$ simulation displays a constantly $0.1 \mathrm{~K}$ higher increase for $\Delta T$ for the resolution T63. For the EC simulation higher differences up to $0.2 \mathrm{~K}$ occur between $200 \mathrm{hPa}$ and $400 \mathrm{hPa}$ and a smaller temperature change for the higher resolution in the lower troposphere. Relatively small resolution-dependent changes for the temperature increase are visible for the EM and ZM simulation up to $200 \mathrm{hPa}$. Concerning the tropical upper troposphere and lower stratosphere, almost every convection scheme (except EC) depicts a higher increase in tem-

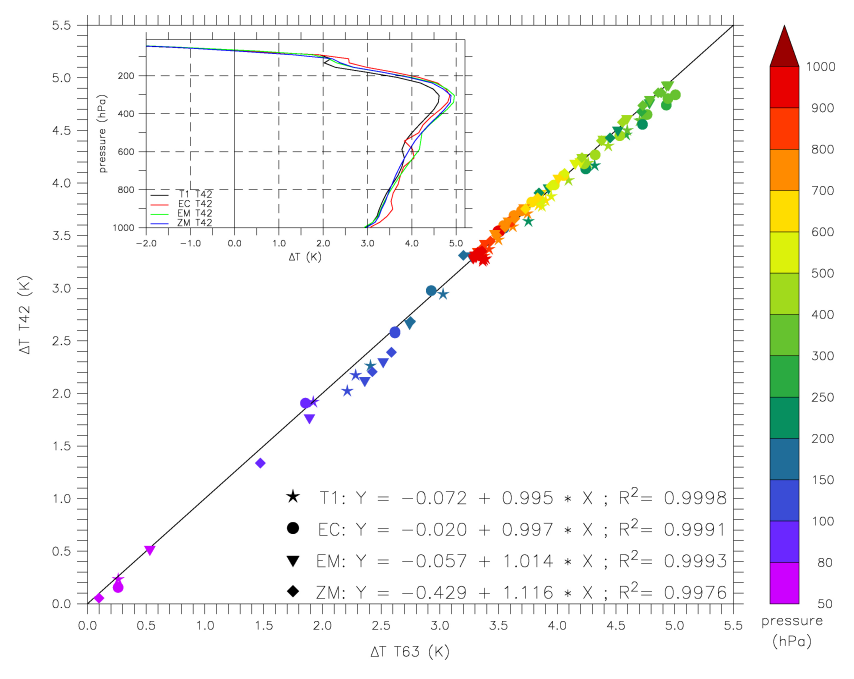

Figure 2. Correlation of the temperature change $\Delta T$ between the resolutions T63 (horizontal axis) and T42 (vertical axis) for the individual simulations distinguished by symbols $(\mathrm{T} 1=$ star, $\mathrm{EC}=$ circle, $\mathrm{EM}=$ triangle and $\mathrm{ZM}=$ diamond) and colour coded with pressure altitude. The inner panel shows the temperature increase $\Delta T$ for the coarser resolution (T42), the same as Fig. 1c. The black line depicts the one-to-one correspondence.

perature $(\approx 0.2 \mathrm{~K})$ between $100 \mathrm{hPa}$ and $200 \mathrm{hPa}$ for the resolution T63. It is suggested that, the higher the resolution, the higher the convective temperature tendency and consequently a temperature profile which tends towards a more moist adiabatic lapse rate. This is consistent with less convective activity for the resolution T63 (see Fig. 4). In addition, the shift of the tropical tropopause towards lower pressure levels is higher for the resolution T63 while changes in cold point temperatures remain the same. Moreover, Fig. 1a and c display on average a $0.5 \mathrm{~K}$ higher temperature increase at the surface and up to $1.5 \mathrm{~K}$ in the upper troposphere in comparison with Bitz et al. (2012), suggesting that the 
(a) $\Delta T_{\mathrm{Var}}$ T63 (global)

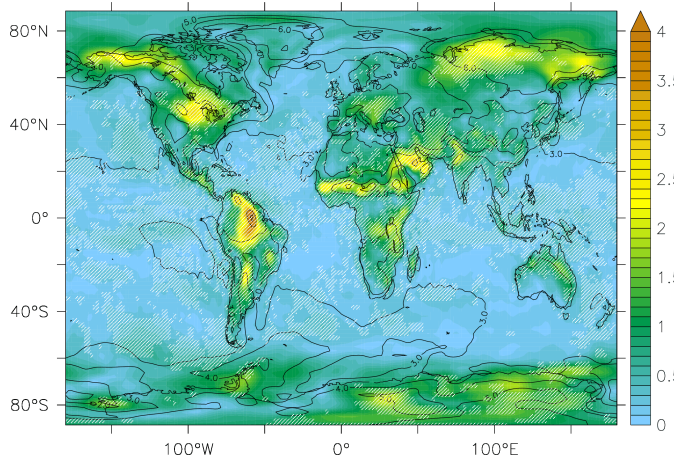

(c) $\Delta T_{\text {Var }}$ T63 (zonal)

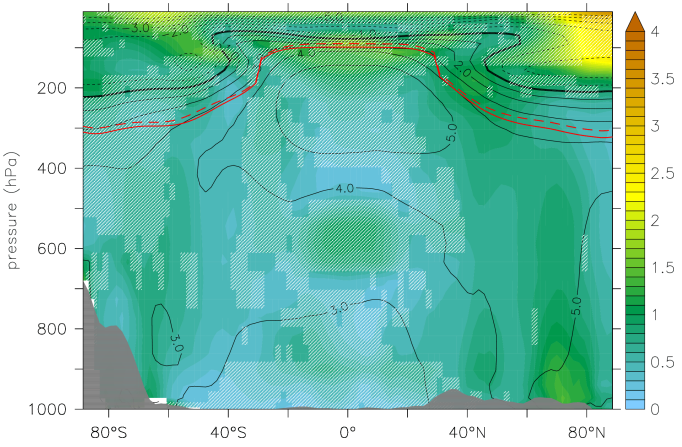

(b) $\Delta T_{\mathrm{Var}} \mathrm{T} 42($ global)

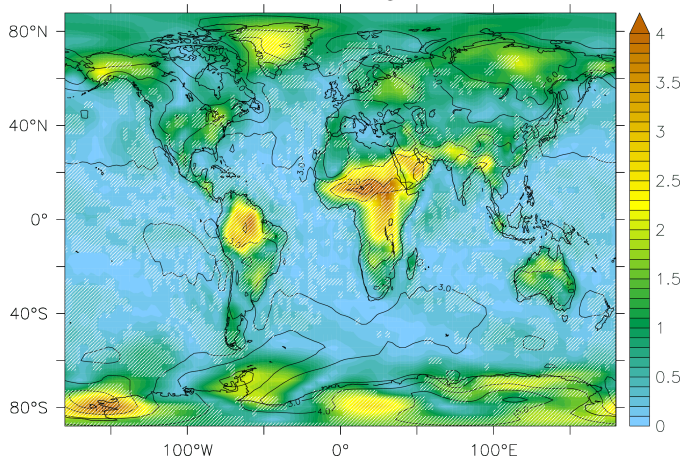

(d) $\Delta T_{\text {Var }}$ T42 (zonal)

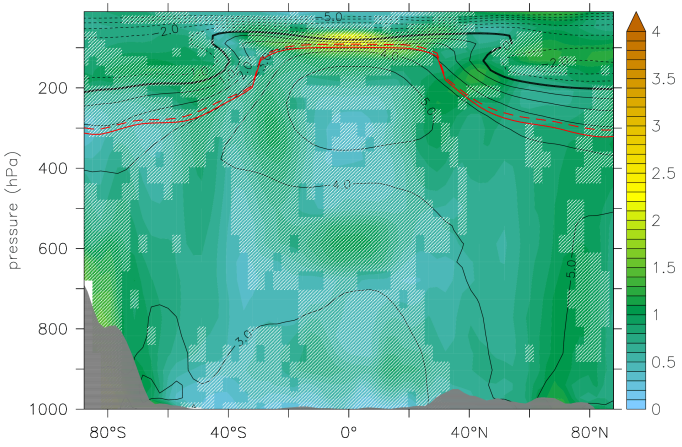

Figure 3. Maximum error $\Delta T_{\mathrm{Var}}$ of the temperature increase in Kelvin (colour coded); the upper panels illustrate regions of high variability for $\Delta T$ for the lowermost model layer, the lower panels show the same for the zonally averaged $\Delta T$. The black contour lines denote the minimal temperature increase $\Delta T_{\min }$ (see Eq. (4)) with an interval of $1 \mathrm{~K}$ (black solid lines indicate positive and black dashed lines negative values). The red solid and dashed lines depict the averaged tropopause height for the reference and $2 \times \mathrm{CO} 2$ simulations, respectively. The white hatched areas show regions where at least 5 of $6 t$ tests capture a significant difference of the temperature change between the different convection schemes (see text).

warmer baseline climate applied in our REF simulations explains this difference.

Figure 2 presents a correlation of the temperature change between the resolution T63 and T42. The individual simulations are distinguished by various symbols and colour coded with pressure altitude. Figure 2 shows that the correlation between the two resolutions is very high $\left(R^{2} \geq 0.9976\right)$ and the linear regression is close to the one-to-one line, particularly below $400 \mathrm{hPa}$ (red to yellow symbols). Nevertheless, a significant tendency of higher temperature changes $\Delta T$ for the resolution T63 is evident in every simulation for pressure altitudes between $50 \mathrm{hPa}$ and $300 \mathrm{hPa}$.

Table 2 compares the simulated temperature increase for the lowermost model layer and their biases compared to the reference simulation $\mathrm{T} 1$. The globally averaged values for $\Delta T$ lie within a range of $3.3 \mathrm{~K}$ to $3.5 \mathrm{~K}$ without significant differences among the resolutions. The EC simulation produces a slightly higher temperature increase compared to the other simulations and an increased inter-annual variability with the resolution T42. In total, the simulated increase in surface temperature is comparable to previous studies (Klocke et al., 2011; Bitz et al., 2012).
Apparently, most of the global mean temperature increase is strongly restricted to the prescribed boundary conditions for the $2 \times \mathrm{CO} 2$ simulation over the oceans, but reveals higher regional variations over the land surface. Figure 3 shows this variability by displaying the maximum error $\Delta T_{\text {Var }}$ (see Eq. (4)) of the temperature increase $\Delta T$ for either the lowermost model layer or the zonal mean induced by a change of the convection parameterisation. This variable helps to identify regions on the globe and within the atmosphere which show a high sensitivity to a change of the convection scheme. In Fig. 3 these regions are explicitly illustrated by green, yellow and brown colours highlighting variations of $\Delta T$ above $1.0 \mathrm{~K}$. These regions encompass the ITCZ in Africa and South America displayed in Fig. 3a, b as well as areas north and south of $60^{\circ}$. The latter specifies zones which vary significantly in snow and ice cover over land between the simulations. Strong variations in high latitudes result from interactions between the boundary layer (parameterisation), the boundary condition and the convection scheme, whereas the variability for the ITCZ region is exclusively determined by the diverse simulation of convection. The most notable feature is visible over the continents Africa and South America, 
$\Delta T_{\mathrm{Var}}$ is approximately $\Delta T_{\min }$ (black contour lines in Fig. 3), which means that the change of the convection parameterisation produces a range of the average temperature increase in these regions between $2 \mathrm{~K}$ and $6 \mathrm{~K}$. Consequently, the impact using a different convection scheme according to the temperature change is large in the ITCZ but negligible with respect to global mean values (see Table 2). The comparison of the resolutions in Fig. 3a and b provides evidence for lower model-to-model fluctuations of the sensitivity in local surface temperature response to convective changes over Africa for the horizontal resolution T63. This indicates that the relative importance of the convection schemes decreases with higher model resolution due to the ability to partly resolve atmospheric phenomena better. The high variability over Africa for the lower resolution is primarily determined by a strong reduction $(\approx 25 \%)$ in precipitation rates (and evaporation rates) in the EC simulation, whereas the other schemes show an increase of about 10 to $20 \%$. Regarding the zonal mean distribution of $\Delta T_{\mathrm{Var}}$, larger values are located in the UTLS and around $600 \mathrm{hPa}$ in the ITCZ (see Fig. 3c, d), pronouncing the temperature variability for these pressure heights shown in Fig. 1. But besides that, a higher variability is also visible around $70^{\circ} \mathrm{N}$ and $80^{\circ} \mathrm{S}$, which indicate regions with a large change in snow and ice cover.

This result points out that differences in the interaction between convection schemes and the boundary layer influence the whole temperature profile of the troposphere, which for this case is also determined by a change of convective triggering (see Sect. 4.2). Additionally, six $t$ tests per resolution $\left(\Delta T_{\mathrm{T} 1} \leftrightarrow \Delta T_{\mathrm{EC}}, \Delta T_{\mathrm{T} 1} \leftrightarrow \Delta T_{\mathrm{EM}}\right.$, etc.) have been performed to identify areas where the temperature change $\Delta T$ is statistically different at a $95 \%$ confidence level. These regions are white hatched in Fig. 3 and cover almost the whole ITCZ and domains of $\Delta T_{\mathrm{Var}}>2 \mathrm{~K}$. Surprisingly, significant differences of $\Delta T$ appear over the oceans at the lowermost model layer although SSTs are prescribed. This result reveals the variable influence of downdrafts on the planetary boundary layer over the oceans.

\subsection{Trigger function/mechanism}

During the simulation the calculation process of the convection scheme is repeated every time step, while the first decision in every cycle defines one grid cell as convective or nonconvective. This determination is done by the so-called trigger function by examining whether the actual atmospheric environment favours the convective ascent of an air parcel or suppress its rise. Each convection parameterisation uses a different kind of trigger mechanism, consequently altering the occurrence of convection as well as the type (shallow, midlevel or deep). A change in this small part of the parameterisation could affect the model climate (Jakob and Siebesma, 2003). The most common trigger function adds a virtual temperature excess (typically $0.5 \mathrm{~K}$ to $1 \mathrm{~K}$ ) to the buoyant air parcel to overcome a potential barrier at cloud base (relevant for
T1, EM and ZM). Another approach for the trigger mechanism, which is pursued by the ECMWF scheme, is the criterion regarding a positive vertical velocity for the air parcel at cloud base (Tompkins et al., 2004). These criteria determine the trigger function and the overall appearance of convection.

The zonal activation of convection for the reference simulations is displayed in Fig. 4a, b. Each bar represents an average activation over $30^{\circ}$ latitude for the overall (deep) convection of one reference simulation displayed by the filled (dashed) bar height. Independent of the resolution, large differences occur among the simulations, in particular for the $\mathrm{T} 1$ and EC simulations. Whereas the EM and ZM simulations produce similar results, the Tiedtke scheme shows a completely different distribution for the deep convective clouds with higher values for high-latitude regions. This can be explained by the additional activation of midlevel convection which is not implemented in the EM and ZM schemes. Nevertheless, the overall activation of $\mathrm{T} 1$ is comparable with the EM and ZM simulations. Although the ECMWF scheme considers midlevel convection, significantly lower values for the activity of total and deep convection are obtained. The distribution for the EC simulation demonstrates that another trigger criterion could lead to a completely different convection occurrence independent of the applied resolution. All in all, a constantly higher convective activity is simulated for the coarser resolution for the T1, EM and ZM simulations. This indicates that a stronger convective temperature tendency is calculated if convection is triggered for the resolution T63 leading to a globally lower lapse rate. The bottom row of Fig. 4 displays the relative change of the convection activation for the $2 \times \mathrm{CO} 2$ simulation. Again, the height of the filled (dashed) bars illustrates the relative change of all (deep) convective events. The largest shift in the activation of the convection scheme is located at the poleward regions in both hemispheres. Changes of $\pm 10 \%$ concerning all convective events and changes up to $\pm 50 \%$ for deep convective events are evident dependent on the selected convection parameterisation. The decrease of the sea ice content and the stronger increase in moisture and temperature in the polar regions leads to more triggering of deep convective events in the $2 \times \mathrm{CO} 2$ simulation. The highly variable change of the activation between the individual simulations for the polar regions explains the temperature variability in Fig. 3. Regarding the latitudinal band between $60^{\circ} \mathrm{S}$ and $60^{\circ} \mathrm{N}$, the T1 simulation features a reduced activation of deep convective events. In contrast, no significant changes are evident for the $\mathrm{EC}, \mathrm{EM}$ and $\mathrm{ZM}$ simulations in these regions.

\subsection{Transport of humidity and short-lived trace gases}

The analysis of the vertical transport of water vapour and other trace gases reveals high differences between the convection parameterisations. Previous studies quantified that the uncertainty in the concentrations of simulated trace gases due to a change of the convection scheme could locally 

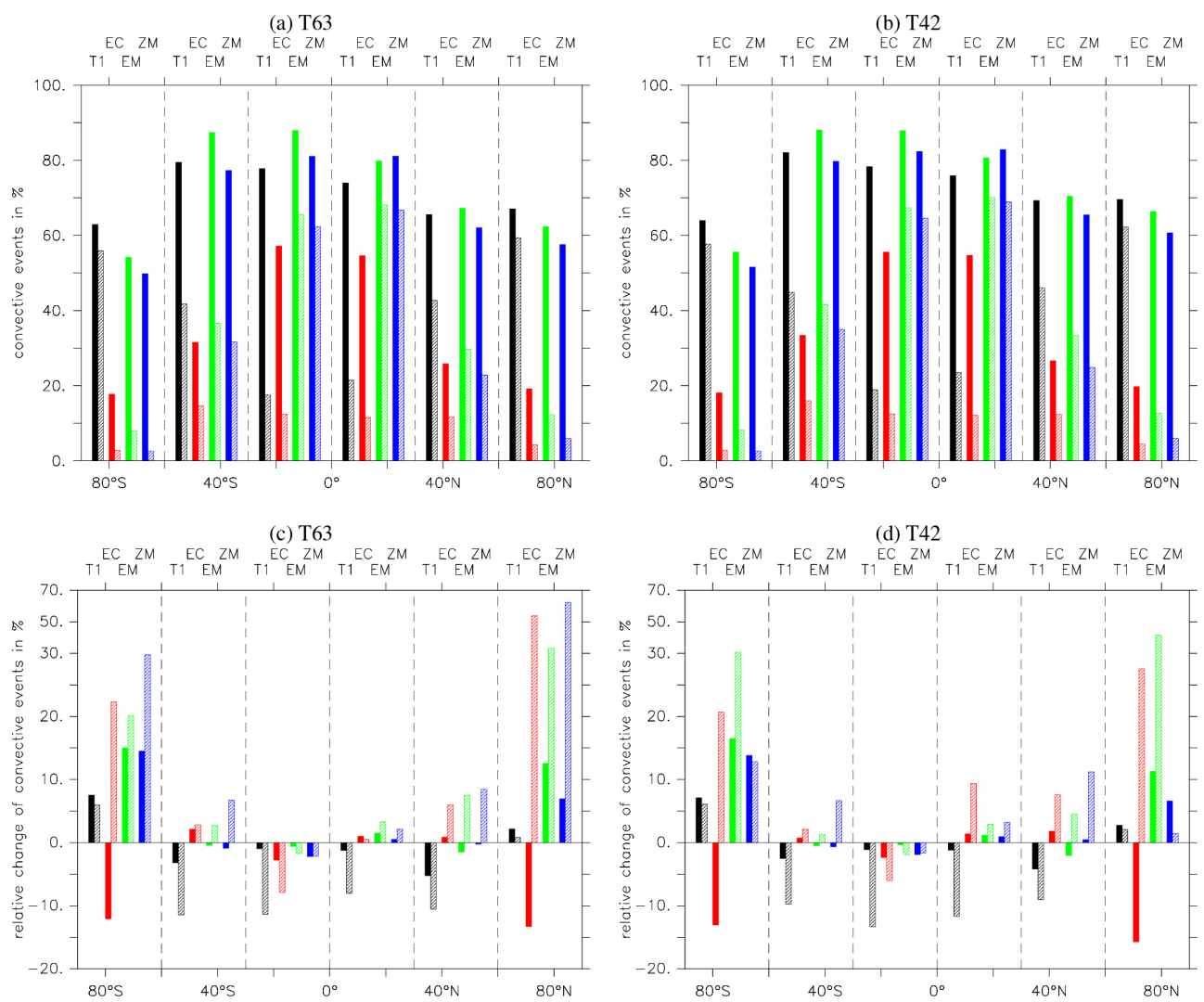

Figure 4. Zonal average activation of the convection scheme in $\%$. Each bar represents an average over $30^{\circ}$ latitude $\left(90^{\circ} \mathrm{S}\right.$ to $60^{\circ} \mathrm{S}, 60^{\circ} \mathrm{S}$ to $30^{\circ} \mathrm{S}$, etc.) for all simulations indicated in the top row of the graphs. The filled bars show the absolute activation of the convection parameterisation and the dashed bars count only deep convective events (and midlevel for T1 and EC). The two upper panels display the activation in the reference simulations and the lower ones the relative difference of the $2 \times \mathrm{CO} 2$ against the REF simulations.

exceed $100 \%$ (Tost et al., 2010; Zhang et al., 2008). Atmospheric convection modifies the distribution of chemical tracers and water vapour by lifting boundary layer air to middle or upper tropospheric levels. Investigating the increase in specific humidity $q$ (Fig. 5), similar characteristics compared to the temperature increase (Fig. 2) can be identified. The inner panel of Fig. 5 shows the global mean increase of specific humidity $\Delta q$ in $\%$ for the resolution T42 indicating a strong increase of up to $90 \%$ at $150 \mathrm{hPa}$. At the same time, this region depicts the largest variability of increasing water vapour between the simulations. The comparison of the resolutiondependent increase of the specific humidity in Fig. 5 reveals different aspects. A high correlation is clearly visible up to $400 \mathrm{hPa}$ close to the one-to-one line, as well as a larger spread for the UTLS region for each respective convection scheme. Taking a closer look at the increase in specific humidity above $100 \mathrm{hPa}$ (purple coloured symbols), a higher increase for the coarser resolution is shown, indicating a higher transmittance of the tropopause layer for transport processes in the resolution T42. Calculated changes of specific humidity at the cold point temperature in the Tropics confirm this statement, revealing a higher increase of on average $4 \%$ for the coarser resolution. In contrast, the T63 simulations point out a significantly higher increase in water vapour between $100 \mathrm{hPa}$ and $300 \mathrm{hPa}$. This result demonstrates that the tropopause operates as a stronger transport barrier for convection in simulations with higher resolutions. Especially, the EC simulation shows a significant lower increase in specific humidity for the resolution T42 up to $100 \mathrm{hPa}$, also indicated by a small value for the slope (0.89) for the linear regression. Apart from that, the change in specific humidity varies by 40 to $60 \%$ at the cold point suggesting that convective transport processes are important for changes in lower stratospheric water content and highly ambiguous for different convection schemes. The high variability of increasing specific humidity for the various simulations in the upper troposphere is consistent with a previous study, which shows strong differences in the simulated water vapour content of the UTLS region dependent on the chosen convection parameterisation (Tost et al., 2006). Therefore, it is hardly surprising that the change in specific humidity is strongly influenced by the applied convection scheme under a doubling of the $\mathrm{CO}_{2}$ concentration. 


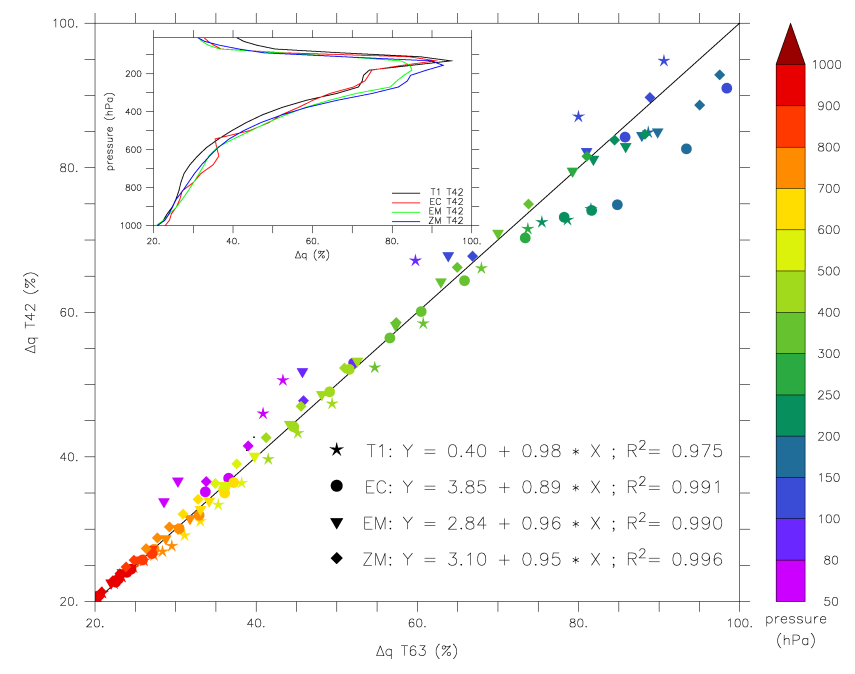

Figure 5. Correlation of the change of specific humidity $\Delta q$ in $\%$ between the resolutions T63 (horizontal axis) and T42 (vertical axis) for the individual simulations distinguished by symbols $(\mathrm{T} 1=$ star, $\mathrm{EC}=$ circle, $\mathrm{EM}=$ triangle and $\mathrm{ZM}=$ diamond $)$ and colour coded with pressure altitude. The inner panel shows the increase in the specific humidity $\Delta q$ in $\%$ for the coarser resolution (T42). The black line depicts the one-to-one correspondence.

Another way to identify the change of vertical transport in the atmosphere is to analyse short-lived trace gases. A typical tracer to investigate convective transport is radon $\left({ }^{222} \mathrm{Rn}\right)$ (Allen et al., 1996; Mahowald et al., 1997; Dentener et al., 1999; Zhang et al., 2008). This chemically inert trace gas is emitted from soil and decays radioactively with a half-life of 3.8 days to lead $\left({ }^{210} \mathrm{~Pb}\right)$ which simultaneously represents the only sink. To simulate the transport of radon a common assumption is a constant emission rate of 1 atom $/\left(\mathrm{cm}^{2} \mathrm{~s}\right)$ over (ice and snow free) land and zero over sea (Turekian et al., 1977; Jacob et al., 1997; Rasch et al., 2000). It has to be kept in mind that this assumption leads to vertical radon profiles which represent to a great extent the convective transport over continental areas and not over oceans. A strict comparison of the vertical radon distribution between the convection schemes requires equal emissions of radon for each simulation. This condition is not satisfied, because the ice and snow cover over land varies in time and place. Therefore, zonally averaged radon ratios are computed which are scaled to the total atmospheric radon column mass for the respective simulation. This approach allows a universal comparison independent of the absolute radon emission. Fig. 6 shows the zonal average vertical distribution of radon for $30^{\circ}$ latitude bands displaying the radon ratio for the REF simulation $\mathrm{T} 1$. The distribution of the EC, EM and ZM simulations are illustrated by relative differences compared to the T1 simulations. A typical zonal distribution of the absolute radon mass (or mixing ratios) has maximum values at ground levels and shows a decrease with increasing height, because of the short residence time (not shown). Looking at the radon ratios in
Fig. 6, the maxima are located around $900 \mathrm{hPa}$ and reduced values for lower pressure levels are visible independent of the latitude band. Within the boundary layer, small radon ratios are calculated because of the comparatively small vertical extent for near-ground levels and thus lower grid box masses. The highest ratios are simulated for the Northern Hemisphere reflecting the larger zonal land amount and associated emissions in these latitudes. Only small differences between the convection schemes are apparent in the lower altitudes of the mid-latitudes. In the ITCZ region significant variations ranging from $-40 \%$ for the lower troposphere up to above $100 \%$ in the UTLS region are evident. The variability of the radon ratios in the Tropics confirms that simulating fast transport is strongly influenced by the convection scheme. The relative change of radon due to an increase of carbon dioxide is illustrated in Fig. 7. Regarding the mid-latitudes and polar regions each convection scheme shows an increase of the radon ratio below $700 \mathrm{hPa}$ of $10 \%$ and a decrease of $-25 \%$ above this pressure altitude indicating a weaker vertical transport. This is in agreement with a decrease of the upward mass flux because of a higher stability (lower vertical temperature gradient) of a warmer climate. In the ITCZ region a reduction of radon ratios between $200 \mathrm{hPa}$ and $400 \mathrm{hPa}$ is simulated and a strong increase above $200 \mathrm{hPa}$ distinguishing a weaker but higher ascent of radon due to a shift of the tropopause (see black dashed and solid line). The distribution below $400 \mathrm{hPa}$ in the Tropics is widely different among the experiments changing the convection schemes. Whereas the EC and ZM simulations simulate higher radon ratios of up to $10 \%$, the others display only minor changes. Apparently, the choice of the convection parameterisation strongly alters the transport of boundary layer air to the free troposphere in the $2 \times \mathrm{CO} 2$ scenario.

\subsection{Cloud radiative forcing and cloud types}

One major concern in the community of climate modellers is the correct representation of cloud radiative effects. This has been discussed for several years and is stated as the largest source of uncertainty in estimating climate sensitivity (Bony et al., 2006; Soden and Held, 2006). Many physical processes related to cloud formation take place on scales which are smaller than usual ESM resolutions and therefore have to be parameterised. For example, subgrid-scale structures of clouds reflecting inhomogeneities of cloud liquid and ice contents can influence radiative fluxes and precipitation rates which are not (or only barely) considered in ESMs (Barker and Raisanen, 2005). The purpose of this section is to identify the strength of interaction between the cloud and convection schemes by examining the change in cloud types and cloud radiative forcing $(\mathrm{CRF})$. We assume that the redistribution of moist air through the different entrainment and detrainment rates parameterised in diverse approaches in the convection schemes produces various cloud types and hence a diverse cloud radiative feedback under alternative climate 

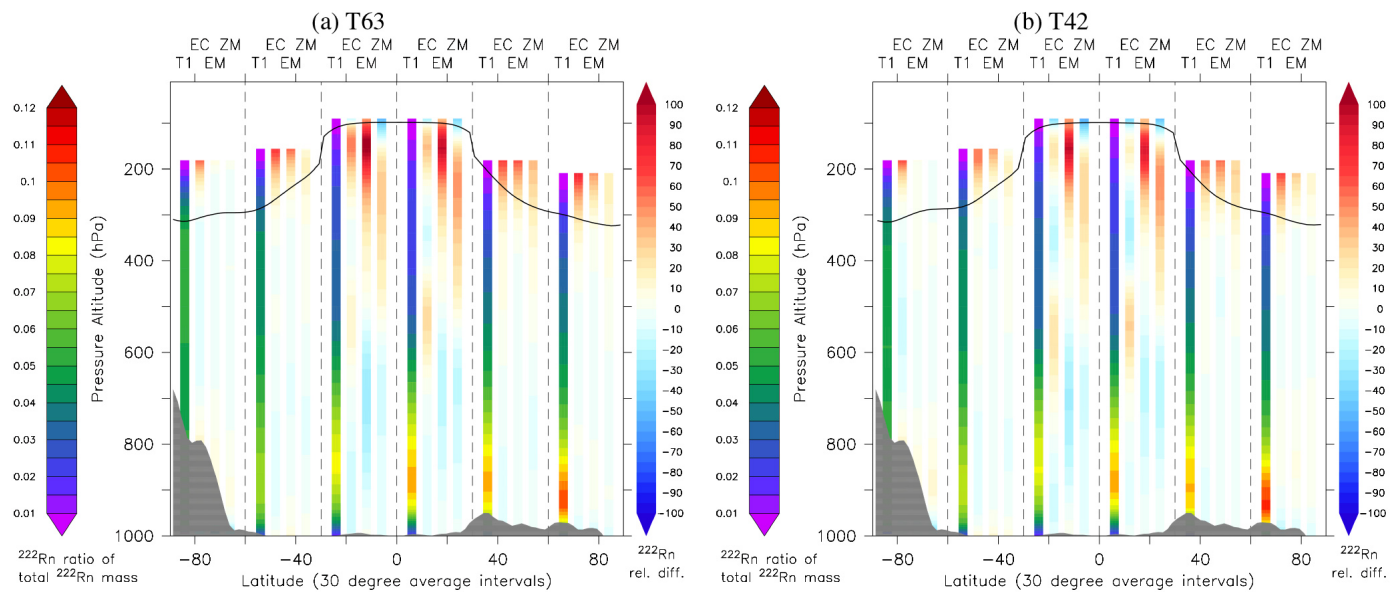

Figure 6. Zonally averaged radon ratios of the total atmospheric radon mass. The vertical axis depicts the pressure altitude and each bar represents an average over $30^{\circ}$ latitude $\left(90^{\circ} \mathrm{S}\right.$ to $60^{\circ} \mathrm{S}, 60^{\circ} \mathrm{S}$ to $30^{\circ} \mathrm{S}$, etc.) for all simulations indicated in the top row of the graphs. The first bar in each bin shows the ratio for the T1 REF simulations using the colour bar on the left side. The other three bars in each bin indicate the relative difference in $\%$ to the Tiedtke simulations using the colour scale on the right-hand side of the panel. The black solid line illustrates the mean tropopause height of the REF simulations and the grey shaded area the zonal mean orography.
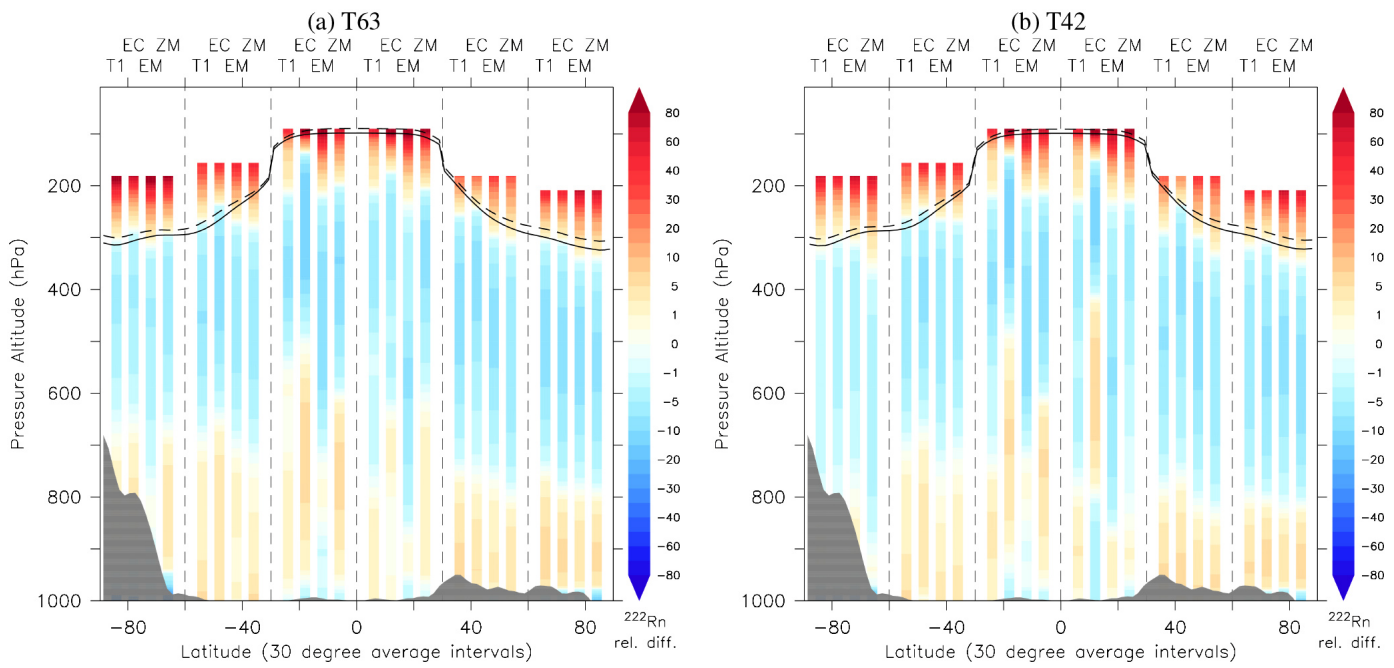

Figure 7. Zonally averaged relative change in radon ratios in the $2 \times \mathrm{CO} 2$ simulation. The vertical axis depicts the pressure altitude and each bar represents an average over $30^{\circ}$ latitude $\left(90^{\circ} \mathrm{S}\right.$ to $60^{\circ} \mathrm{S}, 60^{\circ} \mathrm{S}$ to $30^{\circ} \mathrm{S}$, etc.) for all simulations indicated in the top row of the graphs. The black solid (dashed) line illustrates the mean tropopause height of the REF $(2 \times \mathrm{CO} 2)$ simulations and the grey shaded area the zonal mean orography.

conditions. To identify the differences of cloud-induced radiative flux changes the following calculations have been performed.

The global mean cloud radiative forcing describes the difference between the all-sky and clear-sky radiative fluxes:

$\mathrm{CRF}=F-F_{\mathrm{clr}}$,

where $F_{\text {clr }}$ describes the total net radiative flux at the top of the atmosphere (TOA) under clear-sky conditions and $F$ has the same meaning for all-sky conditions. On a global average Eq. (5) produces a negative value for the CRF, revealing that clouds cool the entire Earth system. Furthermore, one could characterise the magnitude of the CRF by separating the amount into a long-wave $(L W)$ and short-wave $(S W)$ component:

$\mathrm{CRF}=\mathrm{CRF}_{\mathrm{SW}}+\mathrm{CRF}_{\mathrm{LW}}$,

where $\mathrm{CRF}_{\mathrm{SW}}(<0)$ and $\mathrm{CRF}_{\mathrm{LW}}(>0)$ are calculated equally to Eq. (5) for the short-wave and long-wave net radiative fluxes, respectively. The negative sign for the short-wave component results because of the higher reflectivity of clouds with regard to the surface. The positive sign concerning the long-wave component characterises the lower emission temperature of clouds with respect to the surface. Therefore it 

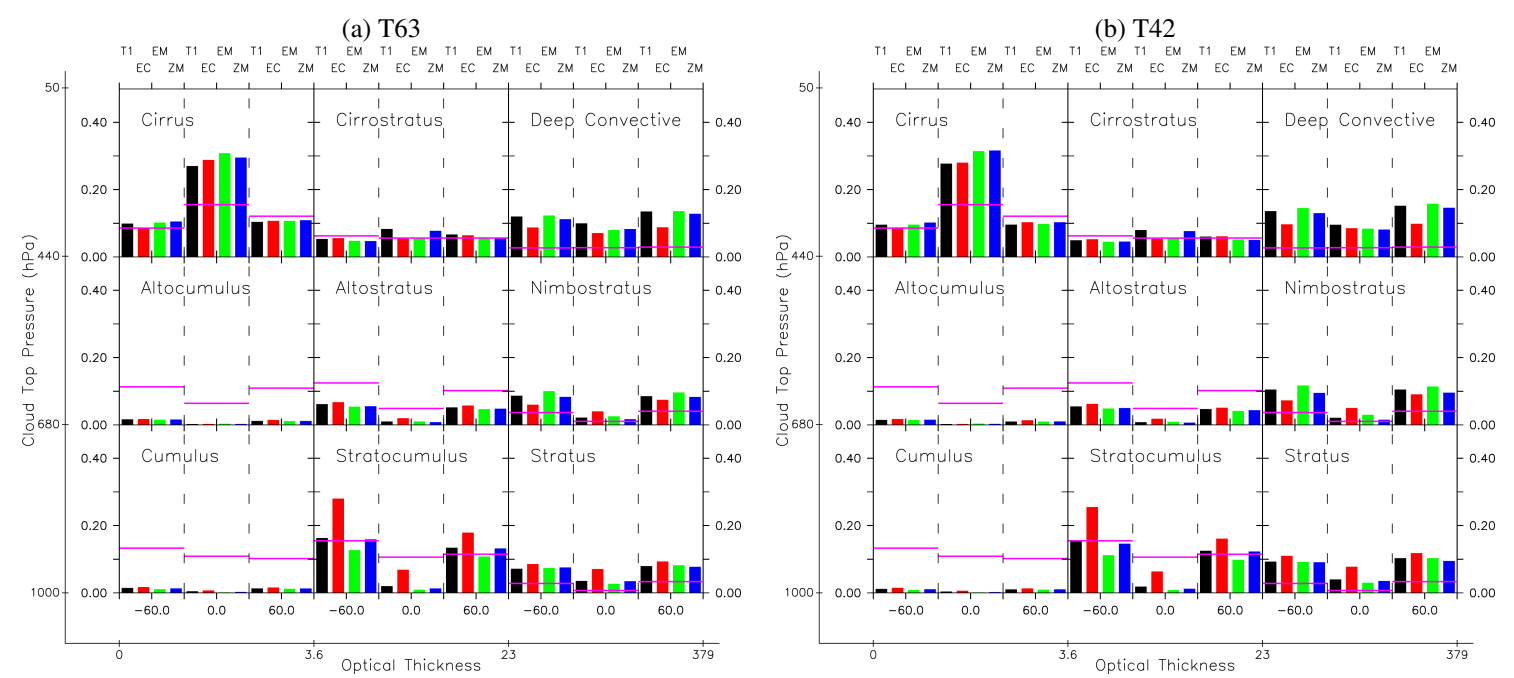

Figure 8. Zonal average occurrence of various cloud types (unit: cloud amount per $\tau-p_{\mathrm{c}}$ bin). Each bar represents an average over $60^{\circ}$ latitude $\left(90^{\circ} \mathrm{S}\right.$ to $30^{\circ} \mathrm{S}$, etc.) for all REF simulations indicated in the top row of the graphs. The purple horizontal lines show multiyear average values from 1984 until 2008 of the ISCCP D1 data set (Pincus et al., 2012). The cloud type classification follows the ISCCP definitions by cloud top height and optical thickness. (Rossow and Schiffer, 1999).

is obvious that the magnitude of these two components is highly variable for different cloud types (Hartmann et al., 1992).

The change in cloud radiative forcing $(\triangle \mathrm{CRF})$ is computed according to Eq. (1) and global mean values are listed in Table 3. In order to explain these results, the fundamental causes which produce a change in cloud radiative forcing have to be analysed. The modification of the Earth's radiation budget is induced by different feedbacks. These feedbacks are related to changing climate processes and consequently linked to the change of physical quantities, including temperature and lapse rate (Planck feedback), water vapour, surface albedo, clouds (amount and type) etc. Analysing $\triangle \mathrm{CRF}$ contains one major problem, known as cloud masking. This effect describes that a change in cloud radiative forcing does not solely result from changes in cloud properties because noncloud feedbacks due to cloud masking are unequally calculated for clear-sky and all-sky flux changes (Soden et al., 2004). According to this, the change in CRF is not equal to the cloud feedback. Nevertheless, the prevailing changes in CRF originate from

(a) changes in cloud cover,

(b) changes of different cloud types (reflecting alterations in cloud top height and optical thickness).

According to (a), the globally averaged cloud cover for the REF simulations vary between 58 to $63 \%$ (not shown). The change in cloud cover is similar in every $2 \times \mathrm{CO} 2$ simulation with a reduction of 2 to $2.5 \%$ inducing a net positive cloud radiative feedback in consistency with Table 3 . However, the changes in short- and long-wave CRF components primarily reveal a highly variable change in cloud types dependent on the convection scheme. To illustrate this, cloud types defined by the International Satellite Cloud Climatology Project (ISCCP) (Rossow and Schiffer, 1999) are calculated online in the model via the ISCCP simulator (Klein and Jakob, 1999; Webb et al., 2001), which categorises cloud types based on their cloud top pressure $\left(p_{\mathrm{c}}\right)$ and optical depth $(\tau)$. Zonal cloud type distributions for the REF simulations are shown in Fig. 8 (including very thin clouds with $\tau<0.3$ ). First of all, it should be mentioned that a comparison with the ISCCP D1 data set (multi-year average values of 1984 until 2008 for the selected cloud types) reveals a strong overestimation of tropical cirrus (partly induced by non-observed very thin cloud structures, i.e. subvisible cirrus in the ISCCP data) as well as optically thick clouds ( $\tau>23 \Rightarrow$ stratus, nimbostratus and deep convective) in all simulations. Cumulus, altocumulus and altostratus are hardly simulated and therefore underestimated compared to the ISCCP data, in agreement with the findings of Zhang et al. (2005) and Raisanen and Jarvinen (2010). Nevertheless, these errors compensate in such a way that radiative equilibrium is achieved and global mean CRF values lie in a reasonable range between -17 and $-27 \mathrm{Wm}^{-2}$ for the reference simulations. Despite that, focusing on the variability of cloud types due to a change of the convection parameterisation, Fig. 8 displays significant variations for thick clouds as well as stratocumulus over all latitudes. The variability easily exceeds $10 \%$ for most cloud types compared with its mean value over all simulations in one zonal region. The change in cloud types is far smaller when comparing the different resolutions than in an exchange of the convection scheme. Consequently, it is important to take into account that convection parameterisations could have a significant influence on the cloud fraction by 

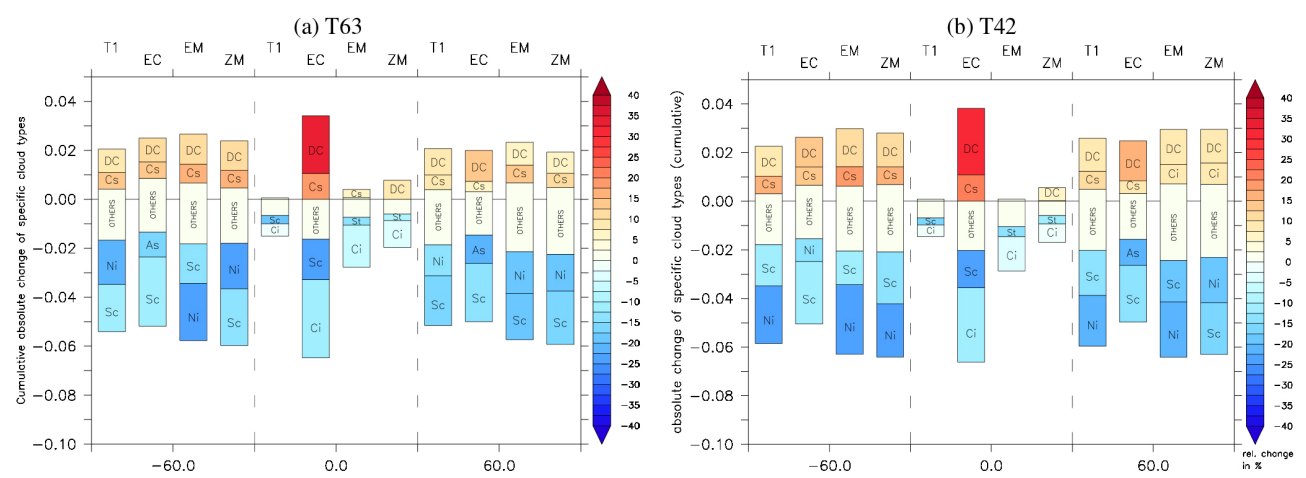

Figure 9. Change of different cloud types in the $2 \times \mathrm{CO} 2$ simulation. Each bar represents an average over $60^{\circ}$ latitude $\left(90^{\circ} \mathrm{S}\right.$ to $30^{\circ} \mathrm{S}$, etc.) for all simulations indicated in the top row of the graphs. The $y$ axis denotes the absolute (cumulative) and the colour bar the relative change in $\%$. The height of one particular bar identifies the absolute increase/reduction of the corresponding cloud type. Only the two highest positive and negative changes are labelled with the following abbreviations: $\mathrm{DC}=$ deep convective, $\mathrm{Cs}=$ cirrostratus, Sc $=$ stratocumulus, $\mathrm{Ni}=$ nimbostratus, $\mathrm{St}=$ stratus, $\mathrm{As}=$ altostratus, $\mathrm{Ci}=$ cirrus .

interacting with the large-scale cloud scheme, as supposed by Raisanen and Jarvinen (2010).

The absolute and relative change in cloud type amount for three $60^{\circ}$ latitudinal bands of the $2 \times \mathrm{CO} 2$ simulations is displayed in Fig. 9, whereas only the two highest (positive and negative) changes are explicitly labelled. At northern and southern mid-latitudes, an increase of deep convective as well as cirrostratus or cirrus clouds of $\sim 25 \%$ is visible. In contrast, nimbostratus, stratocumulus and altostratus clouds are diminished to a greater extent comparing the absolute change in the same region, therefore inducing a positive cloud radiative feedback for all simulations (see Table 3). The differences between the different simulations for these latitudes are small compared to the Tropics. Consequently, the diverse magnitude of $\triangle \mathrm{CRF}$ is primarily caused by high variations of tropical cloud type changes, which is analysed further. In the case of the EC simulation a strong increase of deep convective and cirrostratus clouds compensates the reduction of cirrus clouds inducing a positive change for $\triangle \mathrm{CRF}_{\mathrm{LW}}$, a small reduction of the short-wave CRF component and accordingly a minor positive net $\triangle \mathrm{CRF}$ for the T42 resolution. Close to the equator more deep convective cells are simulated with the convection parameterisation of Zhang-McFarlane-Hack; however, a decrease of the longwave CRF component illustrates that cloud top heights are not significantly increasing because of the higher stability of the warmer atmosphere. The T1 and EM simulations show no changes for convective clouds in the Tropics, only a reduction in cirrus clouds, an effect which is most prominent when using the Emanuel convection scheme entailing a strong positive change in the short-wave component of CRF. The T63 simulations result in similar changes compared to the T42 resolution for the T1, EM and $\mathrm{ZM}$ schemes for $\triangle \mathrm{CRF}_{\mathrm{LW}}$ but smaller values for the short-wave component, because of overall less changes in all cloud types and cloud cover compared to the REF simulations resulting in a smaller change in net cloud radiative forcing. The ECMWF scheme reacts differently, displaying a higher change in $\triangle \mathrm{CRF}_{S W}$ and almost no change for the long-wave component compared to the coarser resolution. Principally, a smaller increase of deep convective and cirrostratus clouds in the Tropics is the reason for this shift in $\triangle \mathrm{CRF}_{\mathrm{LW}}$.

Generally, the change in the long-wave component of CRF is negative for all simulations (except EC T42), but should not be equated with a negative long-wave cloud feedback. As mentioned above, cloud masking effects bias the magnitude of $\triangle \mathrm{CRF}$. The methodology of calculating a change of the cloud radiative forcing in order to have an estimate of the cloud feedback results in an underestimation of the latter (Soden et al., 2004). Taking into account that the offset to the cloud radiative forcing due to cloud masking effects is of the order of 0.48 to $0.68 \mathrm{~W} \mathrm{~m}^{-2} \mathrm{~K}^{-1}$ (Soden et al., 2008), all global net changes in long-wave CRF components would be positive, reflecting a positive long-wave cloud radiative feedback in agreement with Zelinka and Hartmann (2010). Nevertheless, the spread in $\triangle \mathrm{CRF}$ values and cloud type changes indicate a high variability of cloud radiative feedbacks when different convection schemes are applied. In the interest of a quantitative analysis of cloud radiative feedbacks due to different convection parameterisations, it is suggested that radiative kernels should be used (Soden et al., 2008; Zelinka et al., 2012a, b) instead of calculating changes in CRF.

It should be noted that the choice of the cloud scheme alters the variability of cloud type changes in a similar way. In this study the large-scale processes of condensation (cloud and precipitation formation) are based on work of Lohmann and Roeckner (1996) and Tompkins (2002). The sensitivity of other convection parameterisations on different cloud schemes is unknown and has not yet been investigated. This aspect remains unanswered but prompts speculations that other cloud schemes show similar variations by changing the convection parameterisation. 
Table 3. Change in globally averaged CRF as well as the change of the long-wave and short-wave CRF component.

\begin{tabular}{ccccccc}
\hline \multirow{2}{\text{Simulation}}{$\begin{array}{c}\mathrm{T} 63 \\
\text { name }\end{array}$} & $\begin{array}{c}\Delta \mathrm{CRF} \\
\left(\mathrm{W} \mathrm{m}^{-2}\right)\end{array}$ & $\begin{array}{c}\Delta \mathrm{CRF}_{\mathrm{LW}} \\
\left(\mathrm{W} \mathrm{m}^{-2}\right)\end{array}$ & $\begin{array}{c}\Delta \mathrm{CRF}_{S W} \\
\left(\mathrm{~W} / \mathrm{m}^{2}\right)\end{array}$ & $\begin{array}{c}\Delta \mathrm{CRF} \\
\left(\mathrm{W} \mathrm{m}^{-2}\right)\end{array}$ & $\begin{array}{c}\mathrm{T} 42 \\
\left(\mathrm{~W} \mathrm{~m}^{-2}\right)\end{array}$ & $\begin{array}{c}\Delta \mathrm{CRF}_{\mathrm{SW}} \\
\left(\mathrm{W} \mathrm{m}^{-2}\right)\end{array}$ \\
\hline T1 & 1.09 & -0.76 & 1.85 & 1.42 & -0.70 & 2.12 \\
$\mathrm{EC}$ & 0.52 & -0.04 & 0.56 & 0.24 & 0.11 & 0.13 \\
$\mathrm{EM}$ & 1.49 & -0.36 & 1.85 & 2.00 & -0.60 & 2.60 \\
$\mathrm{ZM}$ & 0.87 & -0.20 & 1.07 & 1.27 & -0.19 & 1.46 \\
\hline
\end{tabular}

\section{Conclusions}

One major goal of this study was to investigate the range of uncertainty caused by a change of the convection parameterisation under warmer climate conditions. In total, 16 simulations have been performed with the EMAC model varying the $\mathrm{CO}_{2}$ concentrations $(348 \mathrm{ppm}=$ reference run; $696 \mathrm{ppm}$ $=2 \times \mathrm{CO} 2$ scenario), resolution (T42; T63) and the convection schemes (Tiedtke, ECMWF, Emanuel and ZhangMcFarlane-Hack). The analysis shows significant influences on the temperature and humidity distribution, as well as the transport of short-lived trace gases and cloud properties.

The variability of the global mean temperature change with respect to the vertical profile reveals differences up to $0.5 \mathrm{~K}$ in the middle and upper troposphere. The sensitivity in the mid-troposphere originates most likely from different formulations of the microphysics in the convection parameterisations, especially the treatment of snow and ice formation as well as different calculations of detrainment rates for midlevel convection. Another important contribution is the diversity in the simulated transport of water vapour to the UTLS, which yields a higher uncertainty for the upper troposphere concerning the temperature change. The comparison of the global mean change in surface temperature shows very small differences. Nevertheless, regional variations cover a range from $2 \mathrm{~K}$ to $6 \mathrm{~K}$ in tropical regions. This implies that the uncertainty of regional temperature changes induced by a global warming can easily exceed $4 \mathrm{~K}$ comparing ESMs with different convection parameterisations.

Apart from influencing the temperature profile, transport mechanisms are affected by the chosen convection scheme. In consideration of a changing water vapour content in a $2 \times \mathrm{CO} 2$ scenario, the simulations with coarser resolutions prove that the tropopause is of higher transmittance comparing to the T63 simulations. Hence, a stronger increase in water vapour is visible in the lower stratosphere for the T42 simulations independent of the convection scheme. Furthermore, the analysis of the short-lived trace gas radon verifies that a more stable state of the troposphere in the $2 \times \mathrm{CO} 2$ scenario induces lower upward mass fluxes and consequently a decreased transport of radon up to $200 \mathrm{hPa}$ in the ITCZ region. Additionally, the shift of the tropopause to higher altitudes superimposes the effect of a decrease in mass fluxes and re- sults in higher radon concentrations for the UTLS region. The largest differences according to the change in transport of radon are visible in the lower troposphere ranging from $-20 \%$ to $+20 \%$ for the Tropics. This uncertainty indicates that the different temperature increases over the continents in the ITCZ lead to distinctive initiation of convective transport from the boundary layer dependent on the selected convection parameterisation. Furthermore, the interaction of the boundary layer parameterisation and the convection scheme is sensitive concerning the strength of the calculated upward base mass flux.

In connection with cloud formation, their radiative effects have been analysed for all simulations. The change in cloud radiative forcing has been calculated, revealing differences between the simulations of up to $1.7 \mathrm{~W} \mathrm{~m}^{-2}$. The most important implication is the indirect interaction between largescale cloud schemes and convection schemes resulting in completely different cloud type changes for the Tropics. This high variability of different changes in cloud types induces large differences in cloud radiative feedback and uncovers a new source of uncertainty relating to convection parameterisations. The range of $\triangle \mathrm{CRF}$ could be a relevant indication for different climate sensitivities in coupled atmosphere-ocean GCMs (general circulation models) induced by several convection schemes.

Model intercomparisons often contain different formulations for parameterising convection. Some uncertainties in these comparisons could be directly addressed to the difference in the convection scheme. This study shows that some uncertainties of future climate predictions are linked to the chosen representation of convective clouds as well, and this should be taken into account when comparing different models. It should be pointed out that the results presented here are constrained to the fixed boundary conditions. To acquire a more consistent framework for future studies a coupled atmosphere-ocean GCM should be considered to achieve alternative climate conditions through transient simulations with increasing carbon dioxide concentrations for each convection scheme. These simulations would provide benefits for analysing the change in maritime convection and transport mechanisms over oceans via methyl iodide concentrations (Donner et al., 2007). Moreover, it is important to minimise the uncertainties presented here. A step forward 
could be to compare these results with simulations including a superparameterisation (Khairoutdinov et al., 2005) for near-explicit representation of cloud processes considering subgrid-scale mechanisms through a cloud-resolving model. An advantage of these multiscale models is a better account for low cloud fraction (Wyant et al., 2006) and the interaction between clouds and radiation at unresolved scales (Cole et al., 2005) which seems to be a dominant factor of high uncertainties in the net cloud radiative forcing.

In addition, the development of new convection parameterisations should consider scale awareness (Grell and Freitas, 2014) in order to be applicable under varying model resolutions.

Acknowledgements. We are grateful to M. Ponater for providing data of sea surface temperatures and sea ice contents for the $2 \times \mathrm{CO} 2$ simulations and useful discussions. Furthermore, we wish to acknowledge use of the Ferret program for analysis and graphics in this paper. Ferret is a product of NOAA's Pacific Marine Environmental Laboratory. (Information is available at http://ferret.pmel.noaa.gov/Ferret/). We would like to acknowledge high-performance computing support provided by the computing facilities at the Johannes Gutenberg University and all MESSy developers for support and discussions.

Edited by: J. Quaas

\section{References}

Allen, D. J., Rood, R. B., Thompson, A. M., and Hudson, R. D.: Three-dimensional radon 222 calculations using assimilated meteorological data and a convective mixing algorithm, J. Geophys. Res.-Atmos., 101, 6871-6881, doi:10.1029/95JD03408, 1996.

Arakawa, A.: The cumulus parameterization problem: Past, present, and future, J. Climate, 17, 2493-2525, doi:10.1175/15200442(2004)017<2493:RATCPP>2.0.CO;2, 2004.

Arakawa, A. and Schubert, W. H.: Interaction of A Cumulus Cloud Ensemble With Large-scale Environment .1., J. Atmos. Sci., 31, 674-701, doi:10.1175/15200469(1974)031<0674:IOACCE>2.0.CO;2, 1974.

Barker, H. W. and Raisanen, P.: Radiative sensitivities for cloud structural properties that are unresolved by conventional GCMs, Q. J. Roy. Meteorol. Soc., 131, 3103-3122, doi:10.1256/qj.04.174, 2005.

Bechtold, P., Bazile, E., Guichard, F., Mascart, P., and Richard, E.: A mass-flux convection scheme for regional and global models, Q. J. Roy. Meteorol. Soc., 127, 869-886, doi:10.1256/smsqj.57308, 2001.

Bechtold, P., Chaboureau, J. P., Beljaars, A., Betts, A. K., Kohler, M., Miller, M., and Redelsperger, J. L.: The simulation of the diurnal cycle of convective precipitation over land in a global model, Q. J. Roy. Meteorol. Soc., 130, 3119-3137, doi:10.1256/qj.03.103, 2004.

Bitz, C. M., Shell, K. M., Gent, P. R., Bailey, D. A., Danabasoglu, G., Armour, K. C., Holland, M. M., and Kiehl, J. T.: Climate Sensitivity of the Community Climate System Model, Version
4, J. Climate, 25, 3053-3070, doi:10.1175/JCLI-D-11-00290.1, 2012.

Bony, S., Dufresne, J. L., Le Treut, H., Morcrette, J. J., and Senior, C.: On dynamic and thermodynamic components of cloud changes, Climate Dynam., 22, 71-86, doi:10.1007/s00382-0030369-6, 2004.

Bony, S., Colman, R., Kattsov, V. M., Allan, R. P., Bretherton, C. S., Dufresne, J. L., Hall, A., Hallegatte, S., Holland, M. M., Ingram, W., Randall, D. A., Soden, B. J., Tselioudis, G., and Webb, M. J.: How well do we understand and evaluate climate change feedback processes?, J. Climate, 19, 3445-3482, doi:10.1175/JCLI3819.1, 2006.

Cess, R. D., Potter, G. L., Blanchet, J. P., Boer, G. J., Ghan, S. J., Kiehl, J. T., Letreut, H., Li, Z. X., Liang, X. Z., Mitchel, J. F. B., Morcrette, J. J., Randall, D. A., Riches, M. R., Roeckner, E., Schlese, U., Slingo, A., Taylor, K. E., Washington, W. M., Wetherald, R. T., and Yagai, I.: Interpretation of Cloud-climate Feedback As Produced By 14 Atmospheric General-Circulation Models, Science, 245, 513-516, doi:10.1126/science.245.4917.513, 1989.

Cess, R. D., Potter, G. L., Blanchet, J. P., Boer, G. J., Del Genio, A. D., Deque, M., Dymnikov, V., Galin, V., Gates, W. L., Ghan, S. J., Kiehl, J. T., Lacis, A. A., Le Treut, H., Li, Z. X., Liang, X. Z., McAvaney, B. J., Meleshko, V. P., Mitchel, J. F. B., Morcrette, J. J., Randall, D., Rikus, L., Roeckner, E., Royer, J. F., Schlese, U., Sheinin, D. A., Slingo, A., Sokolov, A. P., Taylor, K. E., Washington, W. M., Wetherald, R. T., Yagai, I., and Zhang, M. H.: Intercomparison and Interpretation of Climate Feedback Processes In 19 Atmospheric Generalcirculation Models, J. Geophys. Res.-Atmos., 95, 16601-16615, doi:10.1029/JD095iD10p16601, 1990.

Charney, J. G.: Carbon Dioxide and Climate:A Scientific Assessment, The National Academies Press, Washington, D.C., 9-10, 1979.

Chen, T., Rossow, W. B., and Zhang, Y. C.: Radiative effects of cloud-type variations, J. Climate, 13, 264-286, doi:10.1175/1520-0442(2000)013<0264:REOCTV>2.0.CO;2, 2000.

Cole, J. N. S., Barker, H. W., Randall, D. A., Khairoutdinov, M. F., and Clothiaux, E. E.: Global consequences of interactions between clouds and radiation at scales unresolved by global climate models, Geophys. Res. Lett., 32, L06703, doi:10.1029/2004GL020945, 2005.

Colman, R.: A comparison of climate feedbacks in general circulation models, Climate Dynam., 20, 865-873, doi:10.1007/s00382003-0310-z, 2003.

Dentener, F., Feichter, J., and Jeuken, A.: Simulation of the transport of Rn-222 using on-line and off-line global models at different horizontal resolutions: a detailed comparison with measurements, Tellus B - Chem. Phys. Meteorol., 51, 573-602, doi:10.1034/j.1600-0889.1999.t01-2-00001.x, 1999.

Donner, L. J., Seman, C. J., Hemler, R. S., and Fan, S. M.: A cumulus parameterization including mass fluxes, convective vertical velocities, and mesoscale effects: Thermodynamic and hydrological aspects in a general circulation model, J. Climate, 14, 3444-3463, doi:10.1175/15200442(2001)014<3444:ACPIMF>2.0.CO;2, 2001.

Donner, L. J., Horowitz, L. W., Fiore, A. M., Seman, C. J., Blake, D. R., and Blake, N. J.: Transport of radon-222 and 
methyl iodide by deep convection in the GFDL Global Atmospheric Model AM2, J. Geophys. Res.-Atmos., 112, D17303, doi:10.1029/2006JD007548, 2007.

Emanuel, K. A. and Zivkovic-Rothman, M.: Development and evaluation of a convection scheme for use in climate models, J. Atmos. Sci., 56, 1766-1782, doi:10.1175/15200469(1999)056<1766:DAEOAC>2.0.CO;2, 1999.

Emanuel, K. A., Neelin, J. D., and Bretherton, C. S.: On Large-scale Circulations In Convecting Atmospheres, Q. J. Roy. Meteorol. Soc., 120, 1111-1143, doi:10.1002/qj.49712051902, 1994.

Grabowski, W. W. and Smolarkiewicz, P. K.: CRCP: a Cloud Resolving Convection Parameterization for modeling the tropical convecting atmosphere, Physica D, 133, 171-178, doi:10.1016/S0167-2789(99)00104-9, 1999.

Grell, G. A. and Freitas, S. R.: A scale and aerosol aware stochastic convective parameterization for weather and air quality modeling, Atmos. Chem. Phys., 14, 5233-5250, doi:10.5194/acp-145233-2014, 2014.

Hack, J. J.: Parameterization of moist convection in the National Center for Atmospheric Research community climate model (CCM2), J. Geophys. Res.-Atmos., 99, 5551-5568, doi:10.1029/93JD03478, 1994.

Hartmann, D. L., Ockert-Bell, M. E., and Michelsen, M. L.: The Effect of Cloud Type On Earths Energy-balance Global Analysis, J. Climate, 5, 1281-1304, doi:10.1175/15200442(1992)005<1281:TEOCTO>2.0.CO;2, 1992.

Hartmann, D. L., Moy, L. A., and Fu, Q.: Tropical convection and the energy balance at the top of the atmosphere, J. Climate, 14, 4495-4511, doi:10.1175/15200442(2001)014<4495:TCATEB>2.0.CO;2, 2001.

Hourdin, F., Musat, I., Bony, S., Braconnot, P., Codron, F., Dufresne, J. L., Fairhead, L., Filiberti, M. A., Friedlingstein, P., Grandpeix, J. Y., Krinner, G., Levan, P., Li, Z. X., and Lott, F.: The LMDZ4 general circulation model: climate performance and sensitivity to parametrized physics with emphasis on tropical convection, Climate Dynam., 27, 787-813, doi:10.1007/s00382006-0158-0, 2006.

Jacob, D. J., Prather, M. J., Rasch, P. J., Shia, R. L., Balkanski, Y. J., Beagley, S. R., Bergmann, D. J., Blackshear, W. T., Brown, M., Chiba, M., Chipperfield, M. P., deGrandpre, J., Dignon, J. E., Feichter, J., Genthon, C., Grose, W. L., Kasibhatla, P. S., Kohler, I., Kritz, M. A., Law, K., Penner, J. E., Ramonet, M., Reeves, C. E., Rotman, D. A., Stockwell, D. Z., VanVelthoven, P. F. J., Verver, G., Wild, O., Yang, H., and Zimmermann, P.: Evaluation and intercomparison of global atmospheric transport models using Rn222 and other short-lived tracers, J. Geophys. Res.-Atmos., 102, 5953-5970, doi:10.1029/96JD02955, 1997.

Jakob, C. and Siebesma, A. P.: A new subcloud model for mass-flux convection schemes: Influence on triggering, updraft properties, and model climate, Mon. Weather Rev., 131, 2765-2778, doi:10.1175/1520-0493(2003)131<2765:ANSMFM>2.0.CO;2, 2003.

Joeckel, P., Sander, R., Kerkweg, A., Tost, H., and Lelieveld, J.: Technical Note: The Modular Earth Submodel System (MESSy) - A new approach towards Earth System Modeling, Atmos. Chem. Phys., 5, 433-444, doi:10.5194/acp-5-433-2005, 2005.

Joeckel, P., Kerkweg, A., Pozzer, A., Sander, R., Tost, H., Riede, H., Baumgaertner, A., Gromov, S., and Kern, B.: Development cycle
2 of the Modular Earth Submodel System (MESSy2), Geosci. Model Dev., 3, 717-752, doi:10.5194/gmd-3-717-2010, 2010.

Johnson, R. H.: Partitioning Tropical Heat and Moisture Budgets Into Cumulus and Mesoscale Components - Implications For Cumulus Parameterization, Mon. Weather Rev., 112, 1590-1601, doi:10.1175/1520-0493(1984)112<1590:PTHAMB>2.0.CO;2, 1984.

Khairoutdinov, M., Randall, D., and DeMott, C.: Simulations of the atmospheric general circulation using a cloud-resolving model as a superparameterization of physical processes, J. Atmos. Sci., 62, 2136-2154, doi:10.1175/JAS3453.1, 2005.

Klein, S. A. and Jakob, C.: Validation and sensitivities of frontal clouds simulated by the ECMWF model, Mon. Weather Rev., 127, 2514-2531, doi:10.1175/15200493(1999)127<2514:VASOFC>2.0.CO;2, 1999.

Klocke, D., Pincus, R., and Quaas, J.: On Constraining Estimates of Climate Sensitivity with Present-Day Observations through Model Weighting, J. Climate, 24, 6092-6099, doi:10.1175/2011JCLI4193.1, 2011.

Larson, K., Hartmann, D. L., and Klein, S. A.: The role of clouds, water vapor, circulation, and boundary layer structure in the sensitivity of the tropical climate, J. Climate, 12, 2359-2374, doi:10.1175/1520-0442(1999)012<2359:TROCWV>2.0.CO;2, 1999.

Lin, J. W. B. and Neelin, J. D.: Toward stochastic deep convective parameterization in general circulation models, Geophys. Res. Lett., 30, 1162, doi:10.1029/2002GL016203, 2003.

Lohmann, U. and Roeckner, E.: Design and performance of a new cloud microphysics scheme developed for the ECHAM general circulation model, Climate Dynam., 12, 557-572, doi:10.1007/s003820050128, 1996.

Mahowald, N. M., Rasch, P. J., Eaton, B. E., Whittlestone, S., and Prinn, R. G.: Transport of (222)radon to the remote troposphere using the model of atmospheric transport and chemistry and assimilated winds from ECMWF and the National Center for Environmental Prediction NCAR, J. Geophys. Res.-Atmos., 102, 28 139-28 151, doi:10.1029/97JD02084, 1997.

Nober, F. J. and Graf, H. F.: A new convective cloud field model based on principles of self-organisation, Atmos. Chem. Phys., 5, 2749-2759, doi:10.5194/acp-5-2749-2005, 2005.

Nordeng, T. E.: Extended versions of the convective parametrization scheme at ECMWF and their impact on the mean and transient activity of the model in the tropics. Technical Momorandum 206, ECMWF Research Department, European Centre for Medium Range Weather Forecasts, Reading, UK, 1994.

Pincus, R., Platnick, S., Ackerman, S. A., Hemler, R. S., and Patrick Hofmann, R. J.: Reconciling Simulated and Observed Views of Clouds: MODIS, ISCCP, and the Limits of Instrument Simulators, J. Climate, 25, 4699-4720, doi:10.1175/JCLI-D-1100267.1, 2012.

Plant, R. S. and Craig, G. C.: A Stochastic Parameterization for Deep Convection Based on Equilibrium Statistics, J. Atmos. Sci., 65, 87-105, doi:10.1175/2007JAS2263.1, 2008.

Raisanen, P. and Jarvinen, H.: Impact of cloud and radiation scheme modifications on climate simulated by the ECHAM5 atmospheric GCM, Q. J. Roy. Meteorol. Soc., 136, 1733-1752, doi:10.1002/qj.674, 2010. 
Randall, D., Khairoutdinov, M., Arakawa, A., and Grabowski, W.: Breaking the cloud parameterization deadlock, B. Am. Meteorol. Soc., 84, 1547-1564, doi:10.1175/BAMS-84-11-1547, 2003.

Rasch, P. J., Feichter, J., Law, K., Mahowald, N., Penner, J., Benkovitz, C., Genthon, C., Giannakopoulos, C., Kasibhatla, P., Koch, D., Levy, H., Maki, T., Prather, M., Roberts, D. L., Roelofs, G. J., Stevenson, D., Stockwell, Z., Taguchi, S., Kritz, M., Chipperfield, M., Baldocchi, D., McMurry, P., Barrie, L., Balkansi, Y., Chatfield, R., Kjellstrom, E., Lawrence, M., Lee, H. N., Lelieveld, J., Noone, K. J., Seinfeld, J., Stenchikov, G., Schwartz, S., Walcek, C., and Williamson, D.: A comparison of scavenging and deposition processes in global models: results from the WCRP Cambridge Workshop of 1995, Tellus B - Chem. Phys. Meteorol., 52, 1025-1056, doi:10.1034/j.16000889.2000.00980.x, 2000.

Ringer, M. A., McAvaney, B. J., Andronova, N., Buja, L. E., Esch, M., Ingram, W. J., Li, B., Quaas, J., Roeckner, E., Senior, C. A., Soden, B. J., Volodin, E. M., Webb, M. J., and Williams, K. D.: Global mean cloud feedbacks in idealized climate change experiments, Geophys. Res. Lett., 33, L07718, doi:10.1029/2005GL025370, 2006.

Roeckner, E., Brokopf, R., Esch, M., Giorgetta, M., Hagemann, S., Kornblueh, L., Manzini, E., Schlese, U., and Schulzweida, U.: Sensitivity of simulated climate to horizontal and vertical resolution in the ECHAM5 atmosphere model, J. Climate, 19, 37713791, doi:10.1175/JCLI3824.1, 2006.

Rossow, W. B. and Schiffer, R. A.: Advances in understanding clouds from ISCCP, B. Am. Meteorol. Soc., 80, 2261-2287, doi:10.1175/1520-0477(1999)080<2261:AIUCFI>2.0.CO;2, 1999.

Soden, B. J. and Held, I. M.: An assessment of climate feedbacks in coupled ocean-atmosphere models (vol 19, pg 3354, 2006), J. Climate, 19, 6263-6263, doi:10.1175/JCLI9028.1, 2006.

Soden, B. J., Broccoli, A. J., and Hemler, R. S.: On the Use of Cloud Forcing to Estimate Cloud Feedback, J. Climate, 17, 3661-3665, doi:10.1175/1520-0442(2004)017<3661:OTUOCF>2.0.CO;2, 2004.

Soden, B. J., Held, I. M., Colman, R., Shell, K. M., Kiehl, J. T., and Shields, C. A.: Quantifying Climate Feedbacks Using Radiative Kernels, J. Climate, 21, 35043520, doi:10.1175/2007JCLI2110.1, http://dx.doi.org/10.1175/ 2007JCLI2110.1, 2008.

Solomon, S., Qin, M., Manning, M., Marquis, M., Averyt, K. B., Tignor, M., Miller, H. L., and Chen, Z.: Climate Change 2007: The Physical Science Basis : Contribution of Working Group I to the Fourth Assessment Report of the Intergovernmental Panel on Climate Change, Cambridge University Press, 8, 629-640, 2007.

Stephens, G. L.: Cloud feedbacks in the climate system: A critical review, J. Climate, 18, 237-273, doi:10.1175/JCLI-3243.1, 2005.

Tiedtke, M.: A Comprehensive Mass Flux Scheme For Cumulus Parameterization In Large-scale Models, Mon. Weather Rev., 117, 1779-1800, doi:10.1175/15200493(1989)117<1779:ACMFSF>2.0.CO;2, 1989.

Tompkins, A., Bechtold, P., Beljaars, A., Benedetti, A., Cheinet, S., Janiskova, M., Köhler, M., Lopez, P., and Morcrette, J.-J.: Moist Physical Processes in the IFS: Progress and Plans, Technical Memorandum 452, ECMWF, 2004.

Tompkins, A. M.: A prognostic parameterization for the subgrid-scale variability of water vapor and clouds in large-scale models and its use to diagnose cloud cover, J. Atmos. Sci., 59, 1917-1942, doi:10.1175/15200469(2002)059<1917:APPFTS>2.0.CO;2, 2002.

Tost, H., Joeckel, P., and Lelieveld, J.: Influence of different convection parameterisations in a GCM, Atmos. Chem. Phys., 6, 54755493, doi:10.5194/acp-6-5475-2006, 2006.

Tost, H., Lawrence, M. G., Bruhl, C., and Joeckel, P.: Uncertainties in atmospheric chemistry modelling due to convection parameterisations and subsequent scavenging, Atmos. Chem. Phys., 10, 1931-1951, doi:10.5194/acp-10-1931-2010, 2010.

Turekian, K. K., Nozaki, Y., and Benninger, L. K.: Geochemistry of Atmospheric Radon and Radon Products, Annual Review of Earth and Planetary Sciences, 5, 227-255, doi:10.1146/annurev.ea.05.050177.001303, 1977.

Wang, Y., Zhou, L., and Hamilton, K.: Effect of Convective Entrainment/Detrainment on the Simulation of the Tropical Precipitation Diurnal Cycle*, Mon. Weather Rev., 135, 567-585, doi:10.1175/MWR3308.1, 2007.

Webb, M., Senior, C., Bony, S., and Morcrette, J. J.: Combining ERBE and ISCCP data to assess clouds in the Hadley Centre, ECMWF and LMD atmospheric climate models, Climate Dynam., 17, 905-922, doi:10.1007/s003820100157, 2001.

Wilcox, E. M.: Spatial and temporal scales of precipitating tropical cloud systems in satellite imagery and the NCAR CCM3, J. Climate, 16, 3545-3559, doi:10.1175/15200442(2003)016<3545:SATSOP>2.0.CO;2, 2003.

Wyant, M. C., Khairoutdinov, M., and Bretherton, C. S.: Climate sensitivity and cloud response of a GCM with a superparameterization, Geophys. Res. Lett., 33, L06714, doi:10.1029/2005GL025464, 2006.

Yanai, M., Esbensen, S., and Chu, J. H.: Determination of Bulk Properties of Tropical Cloud Clusters From Large-scale Heat and Moisture Budgets, J. Atmos. Sci., 30, 611-627, doi:10.1175/1520-0469(1973)030<0611:DOBPOT>2.0.CO;2, 1973.

Zelinka, M. D. and Hartmann, D. L.: Why is longwave cloud feedback positive?, J. Geophys. Res.-Atmos., 115, D16117, doi:10.1029/2010JD013817, 2010.

Zelinka, M. D., Klein, S. A., and Hartmann, D. L.: Computing and Partitioning Cloud Feedbacks Using Cloud Property Histograms. Part I: Cloud Radiative Kernels, J. Climate, 25, 37153735, doi:10.1175/JCLI-D-11-00248.1, 2012a.

Zelinka, M. D., Klein, S. A., and Hartmann, D. L.: Computing and Partitioning Cloud Feedbacks Using Cloud Property Histograms. Part II: Attribution to Changes in Cloud Amount, Altitude, and Optical Depth, J. Climate, 25, 3736-3754, doi:10.1175/JCLI-D11-00249.1, 2012b.

Zhang, G. J. and McFarlane, N. A.: Sensitivity of Climate Simulations To the Parameterization of Cumulus Convection In the Canadian Climate Center General-circulation Model, Atmos. Ocean, 33, 407-446, 1995.

Zhang, K., Wan, H., Zhang, M., and Wang, B.: Evaluation of the atmospheric transport in a GCM using radon measurements: sensitivity to cumulus convection parameterization, Atmos. Chem. Phys., 8, 2811-2832, doi:10.5194/acp-8-2811-2008, 2008.

Zhang, M. H., Lin, W. Y., Klein, S. A., Bacmeister, J. T., Bony, S., Cederwall, R. T., Del Genio, A. D., Hack, J. J., Loeb, N. G., Lohmann, U., Minnis, P., Musat, I., Pincus, R., Stier, P., Suarez, M. J., Webb, M. J., Wu, J. B., Xie, S. C., Yao, 
M. S., and Zhang, J. H.: Comparing clouds and their seasonal variations in 10 atmospheric general circulation models with satellite measurements, J. Geophys. Res.-Atmos., 110, D15S02, doi:10.1029/2004JD005021, 2005. 